\title{
Community and health staff perceptions on non- communicable disease management in primary care in El Salvador: a qualitative study
}

Nicole Vidal

Queen Margaret University

Montserrat León ( $\square$ monselg8@gmail.com )

Hospital de la Santa Creu i Sant Pau Institut de Recerca https://orcid.org/0000-0001-8567-4685

Marta Jiménez

Queen Margaret University

Keven Bermúdez

Queen Margaret University

Pol De Vos

Queen Margaret University

Research article

Keywords: Non-communicable diseases, community health, El Salvador, qualitative methods

Posted Date: October 18th, 2019

DOI: https://doi.org/10.21203/rs.2.16156/v1

License: (9) This work is licensed under a Creative Commons Attribution 4.0 International License. Read Full License

Version of Record: A version of this preprint was published at BMC Health Services Research on May 27th, 2020. See the published version at https://doi.org/10.1186/s12913-020-05249-8. 


\section{Abstract}

Non-communicable Diseases (NCDs) are the leading cause of global mortality and disability, with a rising burdenin low- and middle-income countries. Their multifactorial aetiology, and their requirement of longterm care, imply the need for comprehensive approaches. From 2009, the Ministry of Health (MoH) in El Salvador has developed a national public health system based on comprehensive primary health care. This analysis explores community perceptions related to the management of NCDs in this health system. During three fieldwork periods in 2018 , three complementary qualitative data collection methods were deployed. First, we used illness narrative methodology to document the life histories of people living with a chronic disease and being treated in second and third level health facilities. Second, through social mapping, we analysed support-resources that NCD patients used throughout the process of their illness. Third, semi-structured interviews were conducted with both chronic patients and health personnel working at different levels of the primary health care setting. Participants were recruited through purposive sampling, and a deductive approach was implemented for coding during the analysis phase. After grouping codes into potential themes, a thematic framework was elaborated for each method through a reflexive approach and triangulation of the data. This innovative approach of combining three welldefined qualitative analysis frameworks identified key implications for the implementation of a comprehensive first line approach to NCDs management in resource-poor settings. Following dimensionsare identified: social risk factors, barriers to care, patient resources and pathways to care, trust in community social connections, and strategies for community health promotion and prevention of NCDs. The Salvadoran public health system has been able to strengthen its comprehensive approach to NCDs, combining a clinical approach - including long term follow-up - with a preventive communitybased strategy. The structural collaboration between the health system and the (self)organized community has been key to identify failings, discuss tensions and work out adapted solutions.

\section{Introduction}

Non-communicable diseases (NCDs) are a major health priority in low- and middle-income countries (LMICs). ${ }^{(1)}$ In 2016, over three quarters of NCD deaths (31.5 million) occurred in these countries, with near to half of these deaths before the age of 70.(2) Though largely preventable, these illnesses are the leading cause of global mortality and disability, and have complex social, economic and environmental aetiologies. ${ }^{(3,4)}$ The burden created by NCDs undermines individual and family well-being and hampers social and economic development, with a particular threat to vulnerable populations. ${ }^{(5)}$

In El Salvador, NCDs are a leading cause of early death among the adult population. Lifestyle behaviours such as low consumption of fruit, vegetables and water, excessive consumption of saturated fats and sugary drinks, but also exposure to agrochemicals, are the main risk factors, directly linked to social and structural barriers. During the period of 2011-2015, the Ministry of Health (MoH) recorded 48,554 NCD deaths, with cardiovascular diseases accounting for $12.0 \%$ of the total deaths registered nationwide, followed by chronic kidney disease (CKD) at $6.3 \%$, cancer at $5.4 \%$, and diabetes mellitus type 2 (DM) at 
3.0\%. ${ }^{(6)}$ Though the World Health Organisation (WHO) does not consider CKD to be part of the NCD group, it was included in this study due to its high prevalence in the country.

Since 2009-within a context of important levels of poverty and social violence-the Salvadoran government developed a strong primary health care (PHC) policy, increasing access to care, with emphasis on remote populations. ${ }^{(7)}$ In this context, the current study explores if and how a well-structured and sufficiently resourced PHC system can ensure adequate pathways for diagnosis, care and long-term treatment for people living with NCDs.

Due to the high burden of NCDs, there is a growing interest in effective strategies to address complex community health issues, especially when health systems face significant resource constraints. ${ }^{\left({ }^{8}\right)}$ Hence, our aim was to analyse the extent to which an intensive coalition between the public health care system and an organized community can support a comprehensive approach to NCD care. For this, three complementary qualitative approaches were combined. At the hospital level, we elicited narratives of patients with a long NCD history on their illness experiences and health seeking. In communities, we mapped health care resources reported by patients, and how these were used. And within primary health services we examine the experiences of both patients and PHC providers in the diagnosis and management of NCDs.

\section{Background}

El Salvador, the smallest country in Central America, has suffered several periods of armed conflict during its history. In the $20^{\text {th }}$ century alone, included a military dictatorship from the early 1930 s to 1979 , and a civil war from 1980 to 1992, during which 75,000 civilians were killed. A long and complex process led to a peace agreement in 1992 and the transition to formal democracy. In this period, the Farabundo Marti National Liberation Front (FMLN), a leftist guerrilla organization, became a political party, which later played a key role in the development of the comprehensive health reform. From 1992 until 2008, neoliberal governments ruled the country. This period saw structural neglect of the public health system accompanying health sector privatization, further developing an already dramatic social divided country. (9)

Currently, the war between gangs ("maras")among the young population, remains a serious social problem, leading to displacements and thousands of deaths every year. The UN has classified El Salvador as one of the deadliest countries in the world outside of a war zone, with more than 108 homicides per 100,000 inhabitants in 2015. Young people are the most affected by violence: more than half of the victims of homicide in El Salvador, Guatemala and Honduras in 2015 were under the age of 30 years. El Salvador continues to have one of the highest murder rates in the world with 3,605 homicides per year in $2017 ; 429$ of which were femicides. ${ }^{(10,11)}$

From 2009 until 2018, the FMLN played an important role in the government. The right to health was core to their political programme. The new $\mathrm{MoH}$ embraced and further developed community participation in 
the preparation, development and management of the health reform. ${ }^{(12,13)}$

Over the last decade, El Salvador has developed a strong integrated public health system, in which organized social participation-defined and implemented as a structured democratic space for the accountability of health care institutions-played an essential role in building trust between the public health system and the population. (12)

The Salvadorian approach builds on the extensive experience of the People's Health Movement on how organized communities can support-or even accelerate-the implementation of comprehensive approaches to community health. The struggle for accessible health care has always been part of a broader movement for health equity and social change. ${ }^{(14)}$ Moreover, health providers can play a strong supporting role in strengthening people's empowerment. ${ }^{(15)}$ Opportunities for this depend on the context in terms of national health policies and existing levels of community organisation or involvement. In El Salvador, the National Health Forum (NHF), a broad national movement of organized civil society, strongly supported the rollout of the health reform, encouraging community participation at all levels.

Through its empowering strategies and active mobilisation, the NHF aimed at strengthening the participation of community leaders in the co-management and control over health policies, practices and services. The movement also mobilised in support of the health reform's efforts towards universal access, universal health coverage, and the pursuit of equity. ${ }^{(16)}$

Within this context, the MoH launched its "Multi-sectoral National Strategic Plan towards the Comprehensive Management of Non-Communicable Diseases in El Salvador".. (17) The plan implemented interventions for the prevention and control of NCDs recommended by the WHO Global Action Plan of NCDs 2013-2020. (18)

It addressed three aims: first, the development of programmes for NCD management, aiming at prompt prevention and effective treatment, pursuing an efficient system of early diagnosis, and the development of educational programmes; second, the coordination of activities with other public institutions and with the private sector, for the prevention and control of NCDs, aiming at an integrated and multidisciplinary national programme; and third, multi-sectoral interventions with broad social participation, to reduce NCD morbidity and mortality. Our study addressed the part that social participation played in the implementation of these proposals, and the lessons for structured processes of social engagement with care and prevention of NCDs in other settings of fragility.

Coordinated by a newly created NCD department in the MoH, these aims were translated into protocols and intervention proposals. ${ }^{(17)}$

Our study addressed the part that social participation played in the implementation of these proposals, and the lessons for structured processes of social engagement with care and prevention of NCDs in other settings of fragility'. 
This work relates to other Global Health research from the NIHR Research Unit on Health in Fragility (RUHF), at the Institute for Global Health and Development of the Queen Margaret University in Edinburgh, emphasizing the strengthening the provision of quality care for non-communicable diseases and mental health in fragile settings: Syrian refugees and host communities in Lebanon, fragile communities in Sierra Leone, and El Salvador.

\section{Methodology \\ 3.1 Study setting}

This study was conducted in two urban and five rural locations across five regions throughout El Salvador: the departments of San Salvador and San Miguel (phases 1 and 2),Usulután (phase 2), and Chalatenango, Morazán and Bajo Lempa (Usulután) (phase 3) (Figure 1). The health facilities visited were selected to represent variation in size of health infrastructure, population served, geographical characteristics, and prevalence of chronic conditions (Table 1.). Access to data collection sites was facilitated by members of the $\mathrm{MoH}$, social movement members, and medical staff from the health facilities where data were collected.

\subsection{Study design}

Along with a documentary review, this study used the triangulation of three complementary qualitative methods to give voice to participants and gain an in-depth understanding of patient and provider experiences related to NCD care.

1) The collection of illness narratives of patients with chronic kidney disease (CKD) and diabetes mellitus, through in-depth interviews in a national and a regional third level public hospital.

2) The analysis of social connections of NCD patients, aiming at obtaining an insight in the social networks of NCD patients; therefore, an adapted version was used of a participatory tool that was originally designed for communities affected by conflict to identify their network of social resources. Here, the tool was used to provide detail on the social networks of NCD patients ${ }^{(19)}$, in the specific context of El Salvador.

3) The semi-structured interviews with patients and staff members in primary care aimed at understanding the pathways of NCDs care within the health system from the viewpoint or perception of the participants, emphasizing community perspectives and the role of social participation to strengthen NCD services. One of the objectives was to identify the role of the social movement in NCD care.

Data were collected in three phases, taking place in November 2017, March 2018 and June 2018.

\subsection{Data collection}




\subsubsection{Patient illness narratives using in-depth interviews}

Through in-depth interviews, six illness narratives were collected during the first phase of data collection. Three of the illness narratives were secured with patients at the Rosales Hospital, the main national hospital of El Salvador. A further three were obtained at the Hospital San Juan de Dios in the city of San Miguel, in the eastern part of the country, with a high prevalence of CKD. The eliciting interviews were designed to understand the different pathways of support available. CKD and DM patients were purposively selected for illness narrative interviews, given the high prevalence of these diseases in the country $\left(487,785\right.$ patients with CKD and 459,114 with DM) ${ }^{(20)}$ and also because of the social factors involved in the aetiology of both diseases (e.g. diet, access to fresh water, sedentarism, violence, pesticide use).

The interviews elicited information on the patients' background, family history, social networks and health, with emphasis on detailed patient experiences with treatment initiation, follow-up, care and support, communication with providers at each stage of treatment, and the broader social and structural determinants of health care accessibility and quality.

The illness narratives were developed in the hospital environment (endocrinology unit, nephrology unit and dialysis unit). Hospital settings are supposed to be the last step of care, giving an opportunity to explore the "causes of the causes" and the different stages in the development of the disease and the pathways of care. ${ }^{(21)}$ Furthermore, the information on existing support through social networks and community structures was included.

Illness narratives are a useful means to access patients' perspectives on illness. They provide a means to gain an in-depth understanding of the pathways of care and treatment of people living with NCDs, taking the sociocultural and political context into account. (22)

\subsubsection{Mapping participants' social connections using a social connections mapping tool}

The second phase of this study aimed at getting an insight in the formal and informal support resources available to people with NCDs, by mapping their network of social connections and their levels of trust with the connections identified.

Mapping participants' network of connections was ensured through a series of participatory mapping workshops, designed to elicit awareness of local social connections and resources. Participants were asked about the different people and organizations in their communities they identified to be helpful if encountering problems during the stages of care.

Five workshops of four participants each were carried out to cover communities organized under the auspices of the NHF social movement, as well as those that were not organized under the NHF 
movement. Workshops were held in two urban areas of San Salvador: District 1 (organized) and San Jacinto (non-organized), and three rural areas: Nueva Granada, Usulután (organized); Tierra Blanca, San Miguel (organized); and Pamchimalco, San Salvador (non-organized).

During the workshops, participants were presented with three disease-based problem scenariosdiagnosis, acute episodes, and follow-up in order to determine who they might contact and to whom each of these connections might pass them on to, if necessary. Responses were plotted on paper linking persons or organizations to the problems for which they were accessed.

After mapping social connections and resources in the different stages of care, participants were interviewed individually to determine the level of trust placed in each of the identified sources. For all connections identified, participants were asked to grade the level of trust they placed on each of them. This process was facilitated through a card sorting activity where the researchers produced a set of cards with each of the identified connections written clearly on each card. Participants then graded the cards by placing them in one of three piles representing either no trust in that resource, some or little trust in that resource, or high trust in that resource.

\subsubsection{Semi-structured interviews with NCD patients and staff members in the first line setting}

The third phase of data collection involved conducting semi-structured interviews with NCD patients and their health providers, building on the findings from the illness narratives and social connections mapping. The objective was to gain an extensive understanding of patient and provider experiences with NCD care in the first line setting.

The study population consisted of staff members working in PHC facilities and of patients with one or more NCDs attending these units. Purposive and snowball sampling methods were used to recruit participants. Staff members and patients were initially identified by the coordinators of the health units and interviewed at their place of choice, either in the workplace or domicile.

Interviews were conducted with 14 NCD patients and 12 staff members using a semi-structured interview guide. Patients inclusion criteria was being over 35 years of age, living with an NCD, and receiving care from the PHC units. The age group was determined based on the WHO-defined 'higher risk group' for NCDs. ${ }^{23)}$ Patient interviews covered aspects of their experience seeking and/or receiving care at the PHC facility, and included questions on treatment initiation, care and support, communication with providers at each stage of treatment, and the broader familial and social context of their medicine-taking (or other aspects of care seeking) behaviour.

The 14 NCD patients interviewed suffered from cardiovascular disease, DM and/or CKD (Table 2). The median age of those interviewed was 64 years old. 
Staff member interviews were included to incorporate a comprehensive understanding of the PHC system by presenting the providers' perspective of NCD care. Health professionals working in different levels within PHC were selected to participate (Table 3.)

\subsection{Data management and analysis}

All interviews and participatory workshops were conducted by the researchers in Spanish, and were digitally recorded.

For data analysis qualitative information collected was transcribed. After transcribing, audio recordings were permanently deleted.

Then all qualitative data were coded, both manually and using NVivo Qualitative Analysis Software version 10.0. A deductive approach was used to develop an open coding system around the topics of patient pathways to care, and patient and provider interactions and experiences of care.

The last step involved collating the coded data into a pre-defined thematic framework specific to each phase of data collection (Table 4).

Data collected through each of these methods were analyzed separately, and subsequently triangulated to identify consistencies or variations across the dataset.

\subsection{Ethical considerations}

This study was approved by the National Health Ethics Committee of El Salvador (CNEIS/2018/005_A) and by the ethics committee of Queen Margaret University in Edinburgh. All participants were provided with information sheets detailing the objectives of the study and their rights as participants. Written informed consent was obtained from each participant prior to their involvement, with participants being informed of their right to decline to take part and/or leave at any time.

\section{Findings}

From across the three sources of data collection, the following key issues were identified:

1) social risk factors and barriers to care; 2) patient pathways to care; 3 ) resources available identified through social connections mapping; 4) trust in social connections; 5) community health promotion and prevention of NCDs; management. These are described below.

\subsection{Social risk factors and barriers to care}


Social violence due to the long war and unrest suffered in the country, along with the ongoing disputes among criminal gangs, has strongly affected communities' health and their ability to secure continuity of care. This social violence has a long history, from the period of military dictatorship (1930-1979), over the civil war (1980-1992) and the social consequences of a neoliberal economic and social policy (1992-2008). This protracted situation of social unrest had an important impact on the mental health status of the Salvadorian population. Many chronic patients interviewed related their illnesses to stress situations and shocks derived from this situation. More than a real causal relationship, it illustrates the tensions for the poorer layers of the population during that neoliberal period.

They found I had high sugar, but at the beginning, the doctor told me that maybe it was just because of stress, because look, so much that we lived during the war, for 12 years. That is why one has acquired so much harm. Then, I went to consultation and the family doctor told me that these are the consequences of the war. (Patient with DM)

Health providers identified lifestyle factors such as diet as a major barrier to care, highlighting that participant backgrounds had to be considered in order to facilitate healthcare access.

The biggest challenge is that patients need to comply with taking their medication or following other recommendations. Especially when these recommendations have to do with lifestyle, principally with the diet. (General practitioner)

However, patients emphasized that economic barriers contribute to these risk factors.

It is expensive to maintain a healthy diet. I can't, and not everyone has everything, we can only buy very little. (Man with hypertension and CKD)

\subsection{Patient pathways to NCD care}

Given the above challenges, it was important to consider how these issues affect patient and provider experiences of NCD care. There is a clearly reported pathway a chronic patient follows. In the case of hypertension and DM, patients go to primary care with the onset of symptoms such as fatigue. In some instances, patients may present at the PHC facility because they feel scared due to the ongoing social violence, causing them to have chest pains or even depression.

For me this started because of some problems that the family had with people. The problem was, they told me that they were going to kill a son of mine .... From that I was left with that distress. And from there I got a lot of affliction, I had a lot of sadness with a desire to cry, I had no joy, and a strong pain in my chest. (Patient with hypertension)

Related to CKD, patients present a severe condition of their disease at the moment of diagnosis, hence revealing a big problem of underdiagnoses. Therefore, the hospital is the entry point in many cases. 
Several factors may influence in that they are seen at the hospital level, because they have not been followed previously in the first level of care and they go to the hospital when they are already serious, others because of lack of access. (Intermunicipal Coordinator)

Also, CKD patients with a higher socio-economic status reported that they were diagnosed in private facilities as there is still the belief that paying for medicines means they are better. Patients may also receive diagnosis during or because of an emergency, which often happens when public facilities are closed or there are long distances to get to these facilities.

When I have an emergency, I prefer to go to the private clinic of San Salvador because there are no medicines in La Palma [public PHC centre] that can be given as good as in the private one. In the private clinic I do not wait, they attend you at the time you arrive. (Patient with hypertension).

Health promoters play a very important role in identifying patients at risk of a chronic condition.

Our strategy is based on the fact that health promoters are the eyes of the health centre, of everything that happens in the community, they are the first to tell us that there is a person who might suffer from a chronic disease, knowing that, we schedule a visit to go to that patient's home. (Nurse).

Once patients are diagnosed, the follow-up is normally done in the PHC facilities, where they receive their medication and follow-up examinations; although, people continue preferring specialized care. For this reason, the health reform reinforced the visits of specialized teams to the communities.

"The specialist physicians have programmed approaches to go to the communities, they evaluate the patients and identify those who need to attend a health facility or they leave them in control; in this approach, home visits can also occur and also there is a comprehensive family care visit at their home" (Departmental Coordinator).

The referral system still lacks strong coordination, but has been reported to have improved with the health reform, giving patients a more comprehensive response to managing their disease.

As family doctors, when a patient can no longer be given their medication, or a disease is difficult to control, or if there is an emergency, we refer the patient to the hospital. For example, if it is a renal patient, there is a whole area for that, there they are assessed by an internist, and if [the internist] considers that the patient has to continue their follow-up there, the patient stays there. If not, they send us a referral to continue the patient's follow-up here in PHC, engaging the patient in preventive activities with for example the health educator. (Family doctor).

Continuity of care has been reported to have improved and involves an integrated system of care that guides and tracks patients over time through a comprehensive array of health services, spanning all levels of intensity of care for NCDs. 
The first time I visited the specialized health unit, they requested I stay the whole morning and I saw a lot of health professionals who explained different things about my chronic illness, what I eat for example. (Woman with DM)

\subsection{Available Resources}

The social connections mapping exercise highlighted the resources available to, and used by, participants through the three stages of their illness: diagnosis, acute episodes and follow-up. Five workshops were held: three in rural settings and two in urban settings. Within each location a workshop was conducted in more "organized areas". This were identified and selected by a key stakeholder, the Ministry of Health. Organized areas were defined as those with higher social capital levels and more presence of social organizations, community organizations such as the National Health Forum. Figure 2 shows how the resources were identified and mapped in one of the workshops. Figure 3 shows the resource used for each of the three scenarios: diagnosis, acute episodes and follow-up.

Within the diagnosis scenario: the hospital, as a public institution, is usually the place where people are diagnosed, although, the private sector accounts for high burdens of diagnoses, as many patients reported being diagnosed at their work place (during annual examinations) or in a private clinic.

The same pattern is followed during acute episodes of the disease, participants mainly sought help from the public sector, particularly hospitals. This was reported as a change in the patient behaviour decreasing the attendance to the private sector in case of emergency. This is considered a big achievement of the Health Reform as access to remote communities was improved thanks to the implementation of the community teams. ${ }^{(24)}$ However, emergency situations often occur at times of difficult access to hospitals, e.g. due to limited public transport. This may lead to significant indirect costs. Family members were often called upon to assist with financial support, and to accompany the patient to the hospital.

During the follow-up phase the greatest variety of different resources are used. The first line health services play an important role. The public system following the health reform, with extended first line services including the presence of supporting specialists, reaches out to more remote areas, and patients can ensure a follow-up of their illness in a comprehensive manner. Natural medicine is also widely used, since there is a perception that there is no risk in its use, it is cheap and easy to access. Extensive popular knowledge of these alternative medicines is in evidence.

Overall, in rural communities, private practitioners (mainly naturopaths) were regularly drawn upon during diagnosis and follow-up, due to easy access and more economic options compared to urban areas. Religion is also predominant as an 'institution', as gathering in the church was seen to strengthen community cohesion; it becomes more predominant as the disease progresses. During the follow-up it is where there is a greater use of the religious resource revealing the relevance it has in the management of chronic diseases, especially for those psychosocial aspects. The NHF tackling social inequalities play a 
predominant role. Finally, family support shows to be present throughout the progression of the disease and mainly used for transportation and social support. There is a clear change in health seeking behaviours since the patient is diagnosed up until they are followed-up having strong resilience factors at the community level.

\subsection{Trust in social connections}

As shown in Figure 4, there were higher levels of trust in public institutions. This may have been due to greater trust felt in first levels of care (PHC), relative to trust placed in hospital care. In, addition, access to free medicine following the abolition of fees for both medicines and consultation due to the health reform, may have also constituted a trust factor.

There was varied levels of trust expressed in the private sector. Participants had more confidence in examinations done in private rather than public centres, but there was less trust during the follow-up due to economic constraints.

At the [public] clinic, normal exams are conducted and they do all of that, but they don't give us what we need most, and this is specifically to do with our individual illnesses. For me, it's my kidney and all my organs, and they can't test for this in the clinic. I think a lot of people are dying because of this, because they can't pay for this [private clinic]. (Man with DM)

Regarding religion, the participants commonly referenced confidence in God and felt uplifted by the church environment.

I think God gives us help and strength, because a lot of people I know with these illnesses, have gotten very depressed and even suicidal. That's why I think that being in a group and being in church helps to lift one's spirits. Because God says that he is here. (Woman with DM)

In our study, we included and compared communities with a strong level of organization and communities that had not organized themselves (yet). Participants who belonged to an organized community felt empowered to form local associations. Although overall there was not much trust in other members of the community, due to the current situation of violence, participants from organized communities reported high levels of trust in their communities and believed they could better respond to their health needs.

Thankfully we are part of an organized community, because of this we formed an association. And in that association, we were able to get professional support. So, we had to form our own groups in order to mutually help each other. (Woman with hypertension)

Gender differences were observed while analysing levels of trust at the family level, with some positing higher levels of trust to female over male family members. 


\subsection{Community health promotion and prevention of NCDs}

An interesting aspect of our analysis in El Salvador was the high level of organization at the community level. It was reported by staff members that people had gained strong organization levels during the civil war period and therefore there was a strong commitment of people to participate in decision-making. The $\mathrm{NHF}$ was born from people of the communities which commenced advocating for the right to healthcare in the early 90 s. This community bonds were reinforced due to the need for organized activism for structural change to overcome the current social, economic and political aspects that impact on health.

This perspective implies activist advocacy for comprehensive health policies, in which the structural causes of poverty and inequality are addressed through a whole society approach, linked to an extending network of empowering community activism and organization. In line with the "health in all policies" framework, the community collaborates with the health system by identifying their needs and by participating in the design of strategies to improve the NCD care and follow-up at community level. An example of this was a local radio, set up by a collaboration between the PHC centre of La Palma and the local school, which engages adolescents to promote healthy eating and other healthy lifestyle behaviour through a weekly program, as reported by one of the nurses.

For us, there is strength in counting on social participation, because they are in a way, the guards of the health system... Who better than they to visualize and follow-up, since a lot of the time we are not able to due to work... It is the communities that are organized, or those which the NHF has organized, that participate the most in our programmes, such as vaccinations, or controlling dengue fever and chronic illnesses. In the territories where the NHF is present, the population is very organized. The people know what their obligations are. We collaborate also, but they know that this is a shared responsibility... [empowered communities] know that health is for everyone, it is not just the responsibility of the $\mathrm{MoH}$. It is not just about being cured, but it should be more about prevention. This is where the people of the NHF are helping the most" (Regional Director of Primary Health Care).

\section{Discussion}

In view of the growing burden of NCDs worldwide, this experience in El Salvador on the development of community-based NCD programmes might be useful for other settings.

The essential elements to discuss and adapt to other contexts, are related to the role of the organized community as a complementary approach and support for the health services. (25)

The aim of this type of community-based approaches is to support individuals, families and communities to overcome obstacles towards ensuring continuity of care, from the diagnosis to the follow-up, with the 
guidance of the health services, based on the well-developed NCD guidelines. ${ }^{(26)}$

A study reporting recommendations for the management of NCDs in conflict areas ${ }^{(27)}$ highlights that an integrated, multi- and interdisciplinary approach should be developed, ensuring the provision of quality care, involving community leaders and influential individuals. Such an approach, as reported by Magnusson et al., ${ }^{(28)}$ needs to be grounded in the right to health. This includes the prevention of NCDs and their risk factors, the improvement of access to care, and addressing the social impact of these ailments. This highlights the appropriateness of a strategy under the health in all policies framework as carried out by the NHF.

Over the last 10 years (2009-2019) El Salvador has implemented a national health system with the aim to guarantee universal health coverage. Progress has been made, but the fragile context remains challenging, not only to ensure further progress, but also to maintain what has been realised. ${ }^{24)}$

While private clinics and third level hospitals played an essential role in the diagnosis of NCDs, the first level of care was highly used for the follow-up, specially for the provision of medicines. Psychosocial needs were mainly covered through community support and also through falling back on the religion. Finally, organizations such as the NHF are used to empower patients. This has improved shared decisionmaking, leading to a better understanding of the patients' health needs.

The Latin American current of critical epidemiology ${ }^{29)}$ criticises the concept of 'social determinants of health' on the basis of its fragmented analysis of the social reality. They advance the concept of 'social determination of health', as this approach emphasizes the determining influence of the overarching structural inequalities and the skewed power relations at all levels, which helps us to better understand the complex interactions of these layers on the social and health reality of communities and individuals.

This public health current explicitly links their analysis to organized activism for structural change, ${ }^{(30)}$ advocating for an extending network of empowering community activism and organization. ${ }^{31,32)}$ Consequently, health promotion then refers to a process where individuals organize and act to increase control over factors related to their individual and collective health. ${ }^{(33,34)}$

While this approach is widely embraced in communities that engage in the NHF, this type of organized engagement has a clearly political stand, implying a continuous struggle to maintain their influence on local health policies through social mobilisation.

While over time the number of organized communities and their impact have been increasing, their focus is mainly on rural areas, much less in the cities. Moreover, other social phenomena cause contrasting dynamics: youth gangs create high levels of social violence, related to the enormous economic divide in the country.

Political accountability mechanisms ensured through the NHF constituted an important factor to rate higher trust in the health system performance. Accordingly, our study found that quality of care issues, 
including availability of medicines, were strongly associated with overall public satisfaction with the health system. While drug or lab-test shortages, led to mistrust of public health system performance, at the same time, participants reported greater trust in medicines which they had to pay for, compared to the free $\mathrm{MoH}$ medicines.

Despite free health services, patients are often forced to pay transportation and supply costs for essential services. As health care costs within a household increase, families are often forced to divert resources marked for other important purchases, borrow money, or even sell possessions to afford care. These financial barriers were predominant in the discourse related to a low rating of the public institutions.

\section{Limitations}

The complexity of the sociocultural, political and economic context of El Salvador must be noted. The periods of fieldwork might have been too short to gain an overall in-depth knowledge of this context. Moreover, the high level of violence in important parts of the country limited the fieldwork possibilities. Many of these challenges were partially solved thanks to the support and accompaniment of key Salvadorian stakeholders.

This study was conducted between November 2017 and January 2019. The results of the national elections in February 2019 led to a government change, which might imply important changes in the health system analysed here.

\section{Conclusions}

The complementary research methods and the different groups of participants (patients, health personnel and health system coordinators) all identified similar strengths and obstacles.

The combined use of different research methods proved effective for obtaining an in-depth understanding of NCD management strategies in El Salvador, and could serve to guide analyses in function of policy-making in other fragile contexts.

The generation of equitable health policies that pursue accessible quality services is an essential first step to improve access and continuity of care for NCDs. But the Salvadorian experience also shows that a strong and well-organized involvement of the communities can positively influence health care access at the community level, while also promoting a prevention culture.

Participants insisted on the strengthening of healthy lifestyle initiatives adapted to their sociocultural and economic contexts, focussing on children and youngsters. The promotion of community peer support groups for NCDs was advocated, where patients can learn from each other. And finally, more attention is advocated towards the prevention and early diagnosis of renal insufficiency, linked to pesticide intoxication, the so called chronic interstitial nephritis of agricultural communities (CINAC). 


\section{Declarations \\ Funding}

This study was supported by the NIHR Research Unit on Health in Situations of Fragility, through the NIHR Global Health Research Programme 16/136/100.

\section{Competing interests}

The authors declared no conflicts of interest with respect to the research, authorship, and/or publication of this article.

\section{Authors' contributions}

N. V., M.L and M. J. elaborated the manuscript, researched the data, and contributed to the discussion; P. D. V., and K. B. contributed to the discussion, and reviewed and edited the manuscript. P. D. V. coordinated the whole study.

\section{Acknowledgements}

This research was possible thanks to support from members of the Ministry of Public Health

Policies, the National Health Form (FNS) and the Public health policies observatory-

University of El Salvador, which facilitated access to different communities that might

otherwise be difficult to reach because of ongoing social violence.

\section{References}

(1) Pan American Health Organization (PAHO). Plan of action for the prevention and control of noncommunicable diseases in the Americas 2013-2019. 2014; Available at:

https://www.paho.org/hq/dmdocuments/2015/action-plan-prevention-control-ncds-americas.pdf. Accessed 03/01, 2018.

(2) World Health Organization (WHO). Global Health Observatory data: NCD mortality and morbidity. Available at: https://www.who.int/gho/ncd/mortality_morbidity/en/. Accessed 02/06, 2019.

(3) Beaglehole R, Bonita R, Alleyne G, Horton R, Li L., Lincoln P., et al. UN high-level meeting on noncommunicable diseases: addressing four questions. Lancet 2011;378:449-455. 
(4) World Health Organization (WHO). Non-communicable diseases and mental health. 2011; Available at: http://www.who.int/nmh/newsletter_december_20091211_en.pdf. Accessed 04/01, 2018.

(5) Asamblea General de Naciones Unidas. 28.Declaración Política de la Reunión de Alto Nivel de la Asamblea General sobre la Prevención y el Control de las Enfermedades No Transmisibles. 2011;A/66/L.1:3-14.

(6) Ministerio de Salud El Salvador. Resultados relevantes encuesta nacional de enfermedades crónicas no transmisibles en población adulta de El Salvador: ENECA-ELS 2015. 2015.

(7) Ministerio de Salud El Salvador. Technical Guidelines for Family ECOs and Specialized ECOs 2017.

(8) Anderson LM, Adeney HL, Shinn C, Krause LK, Safranek S. Community coalition-driven interventions to reduce health disparities among racial and ethnic minority populations ( Protocol). Cochrane Collab. 2012;(6)

(9) Van Der Borgh C. The Politics of Neoliberalism in Postwar El Salvador. International Journal of Political Economy 30 (1); 36-54.

(10) Amnesty International. Home sweet home? Honduras, Guatemala and El Salvador's role in a deepening refugee crisis. 2016.

(11) Amnesty International. El Salvador 2017/2018. 2019; Available at: https://www.amnesty.org/es/countries/americas/el-salvador/report-el-salvador/, 03/06/2019.

(12) Rodriguez MI. Construyendo la esperanza: estrategias y recomendaciones en salud. 2009; Available at: https://www.paho.org/els/index.php?option = com_docman\&view = download\&alias = 658-politicanacional-de-salud-construyendo-la-esperanza\&category_slug = documentacion-tecnica-1\&ltemid = 364 . Accessed 03/01, 2018.

(13) Barten F, Rovere M, Espinoza E. Reforma de salud: un contexto adverso para el desarrollo de la atención primaria de salud integral en El Salvador.

Salud para todos: Una meta posible Pueblos movilizados y gobiernos comprometidos. 2 nd ed.: Ministerio de Salud, El Salvador; 2010.

(14) De Ceukelaire W, De Vos P. Social movements are key towards universal health coverage. Lancet 2009; 374: 1888.

(15) Van Olmen J, Criel B, Devadasan N, Pariyo G, De Vos P, Van Damme W, Van Dormael M, Marchal B, Kegels G. Primary Health Care in the 21st century: primary care providers and people's empowerment. Tropical Medicine and International Health 2010; 15 (4): 386-390. 
(16) Ministerio de Salud El Salvador. Política Nacional de participación Social en Salud: Sistema Nacional de Salud. 2009.

(17) Ministerio de Salud El Salvador. Plan Estratégico Nacional para el Abordaje Integral de las Enfermedades Crónicas No Transmisibles en El Salvador. 2017.

(18) World Health Organization (WHO). 'Best buys' and other recommended interventions for the prevention and control of noncommunicable diseases. Global Action Plan for the Prevention and Control of Non-communicable Diseases 2013-2020 2017:Appendix 3.

(19) Strang A, O’Brien O. "Who can I turn to? Mapping social connections, trust and problem-solving among conflict-affected populations". Tearfund 2017.

(20) Ministerio de Salud El Salvador. Resultados relevantes encuesta nacional de enfermedades crónicas no transmisibles en población adulta de El Salvador: ENECA-ELS. 2015.

(21) Diez Roux AV. Residential environments and cardiovascular risk. Journal of Urban Health 2003;80(4):569-89.

(22) Bury M. Illness narratives: fact or fiction? Sociology of Health and IIIness 2001;23(3):263-285.

(23) World Health Organization (WHO). Non-communicable Diseases Country Profiles. 2014.

(24) Hernández Reyes A. Primary health care as the foundation of El Salvador ' s health system reform. Pan Am J Public Heal. 2018;42:1-5.

(25) Nissinen A, Berrios X, Puska P. Community-based noncommunicable disease interventions: lessons from developed countries for developing ones. Bull World Health Organ 2001;79(10):963-970.

(26) World Health Organization (WHO). Health promotion glossary Available at: http://apps.who.int/iris/bitstream/handle/10665/67246/WHO_HPR_HEP_98.1_spa.pdf;jsessionid = 12CA4D6728895543BBE2374813A73304?sequence. Accessed 03/01, 2018.

(27) Aebischer Perone S, Martinez E, du Mortier S, Rossi R, Pahud M, Urbaniak V, et al. Non-communicable diseases in humanitarian settings: ten essential questions. Conflict and Health 2017;11(17).

(28) Magnusson RS, Patterson D. The role of law and governance reform in the global response to noncommunicable diseases. Globalization And Health 2014;10(44).

(29) Breilh J. Latin American critical ('Social') epidemiology: new settings for an old dream. International Journal of Epidemiology 2008;37(4):745-750.

(30) Breilh J. La determinación social de la salud como herramienta de transformación hacia una nueva salud pública. Rev Fas Nac Salud Pública 2013;31(Sup 1):S13-S27. 
(31) Ashworth H. Opinion: A Whole-of-Government, Whole-of Society Approach Needed to Tackle NCDs. GBC Health 2018.

(32) Addy NA, Poirier A, Blouin C, Drager N, Dubé L. Whole-of-society approach for public health policymaking: a case study of polycentric governance from Quebec, Canada. Annals of the New York Academy of Sciences 2014;1331:216-229.

(33) Ministerio de Salud El Salvador. Política nacional de participación social en salud. 7 de diciembre del 2012. Acuerdo No. 1889 San Salvador. 2012.

(34) World Health Organization (WHO). Primary health care: now more than ever. 2008.

(35) Bermudez K, Orantes C, León M, Jiménez M, Vidal N, Vos P De. Meso-American Nephropathy in El Salvador: Increasing Farmer Participation in MeN Prevention Efforts. Occup Dis Environ Med [Internet]. 2019;07(02):50-63. Available from: http://www.scirp.org/journal/doi.aspx?DOI = 10.4236/odem.2019.72005

\section{Tables}

Table 1: Estimated number of population affected by NCD by region, area of residence and sex in the adult population of El Salvador (6)

\begin{tabular}{|l|l|l|l|}
\hline & $\begin{array}{l}\text { Diabetes } \\
\text { Mellitus } \\
\text { (DM) }\end{array}$ & $\begin{array}{l}\text { Hypertension } \\
\text { (HBP) }\end{array}$ & $\begin{array}{l}\text { Chronic Kidney disease } \\
\text { (CKD) }\end{array}$ \\
\hline NATIONAL LEVEL & 487,875 & $1.446,381$ & 459,114 \\
\hline REGION & \multicolumn{3}{|l|}{} \\
\hline Occidental (Ahuachapán, Santa Ana, Sonsonate) & 86,524 & 296,275 & 74,181 \\
\hline Central (Chalatenango, La Libertad) & 52,274 & 141,189 & 23,634 \\
\hline $\begin{array}{l}\text { Paracentral (Cuscatlán, La Paz, Cabañas, San } \\
\text { Vicente) }\end{array}$ & 53,799 & 180,519 & 82,133 \\
\hline $\begin{array}{l}\text { Oriental (Usulután, San Miguel, Morazán, La } \\
\text { Unión) }\end{array}$ & 101,084 & 297,210 & 150,990 \\
\hline Metropolitana (San Salvador) & 194,194 & 531,187 & 128,176 \\
\hline SETTING & \multicolumn{3}{|l}{} \\
\hline Urban & 326,166 & 916,778 & 237,630 \\
\hline Rural & 161,709 & 529,602 & 221,484 \\
\hline SEX & \multicolumn{2}{|l}{} \\
\hline Male & 179,708 & 604,184 & 283,905 \\
\hline Female & 308,167 & 842,196 & 175,210 \\
\hline
\end{tabular}

Table 2: Patient interviews 
Cardiovascular disease

Diabetes Mellitus type 2

Chronic Kidney Disease

Total

\begin{tabular}{|l|}
\hline $\mathbf{N}$ \\
\hline 9 \\
\hline 3 \\
2 \\
14 \\
\hline
\end{tabular}

Table 3: Staff interviews

\begin{tabular}{|c|c|c|}
\hline PRIMARY HEALTH CARE STAFF & PROFESSIONAL PROFILE & $\mathbf{N}$ \\
\hline \multirow[t]{3}{*}{ Coordination level } & Departmental Coordinator (1) & \\
\hline & Intermunicipal coordinator (2) & \\
\hline & Regional coordinator (1) & \\
\hline \multirow[t]{8}{*}{ Interdisciplinary PHC team } & Health educator (1) & 8 \\
\hline & Sanitary inspector (1) & \\
\hline & Medical student in year of social service (1) & \\
\hline & General practitioner (1) & \\
\hline & Family doctor (1) & \\
\hline & Nurses (1) & \\
\hline & Pharmacist (1) & \\
\hline & Laboratory technician (1) & \\
\hline Total & & 12 \\
\hline
\end{tabular}

Table 4: Thematic categories pre-defined to conduct along the three phases of data collection 


\section{Illness narratives}

1) Social determinants of care

2) Patient pathways

3) Health systems issues (e.g. costs of care, waiting times, quality of care)

\section{Mapping social connections and trust allocation}

1) Public institutions (e.g. primary health care centres, public hospitals, maternity health centres, social insurance services)

2) Private institutions (e.g. private clinics, private hospitals, private doctors, naturopath)

3) Organisations (including local and international NGOs)

4) Community (e.g. neighbours, community associations)

5) Family (e.g. immediate or extended family members)
Semi-structured interviews with NCD patients and staff members in the PHC setting
1) Primary health care in El Salvador (including organization and coordination of care, evolution of the country's health system, accessibility and barriers to care)

2) Chronic disease management in the PHC system (including prevention and promotion of care, pathways to care, quality of care and barriers to care)

3) Community engagement

\section{Figures}




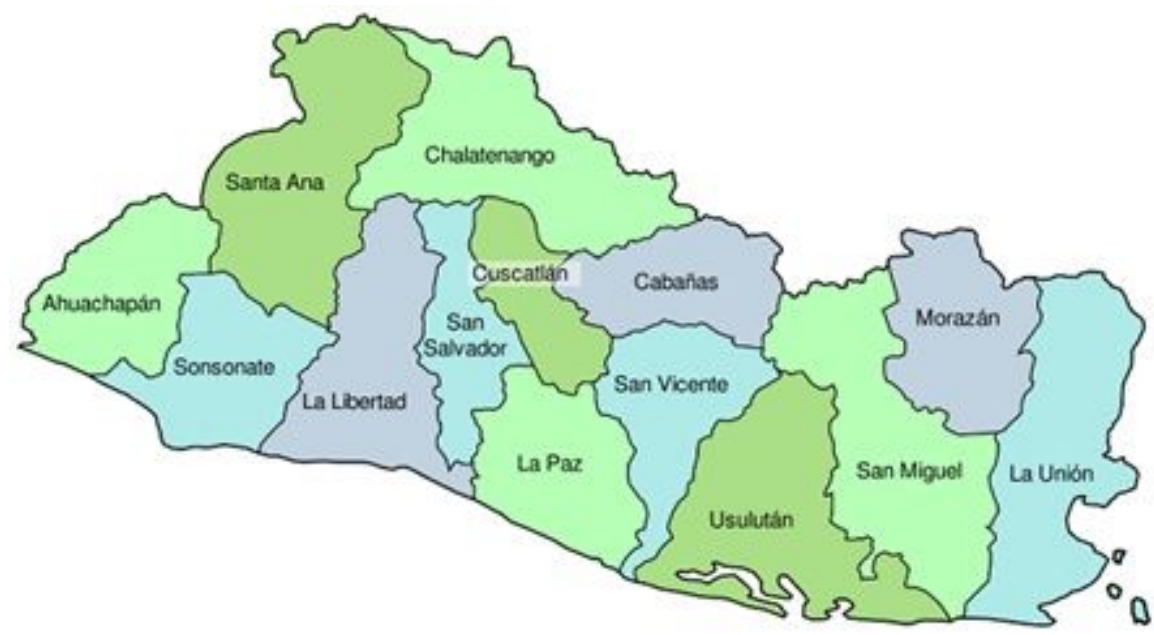

Figure 1

Departmental map of El Salvador

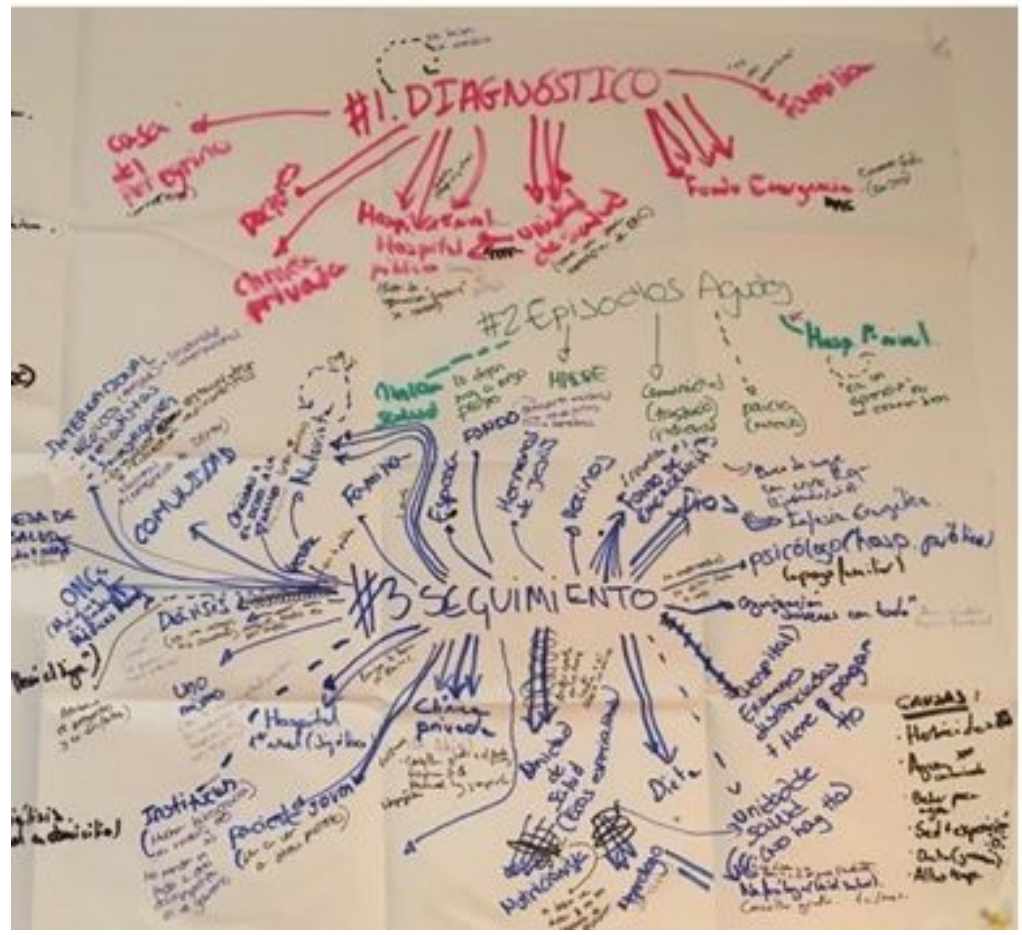

Figure 2

Workshop map of organized rural community 


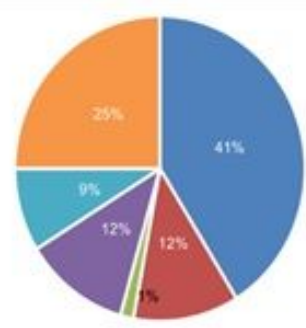

- PUBUC INSTITUTION - PRIVATE SECTOR - ORGANZATONS - COMMUNITY
Resources used during diagnosis
Resources used during acute episode stage

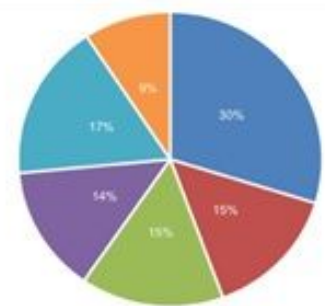

- PUBUC INSTITUTION * PRNATE SECTOR

-REUGION ORGANIZATIONS - COMMUNITY - Family

Resources used during follow-up stage

\section{Figure 3}

Resource used along the three scenario: diagnosis, acute episodes and follow-up stage

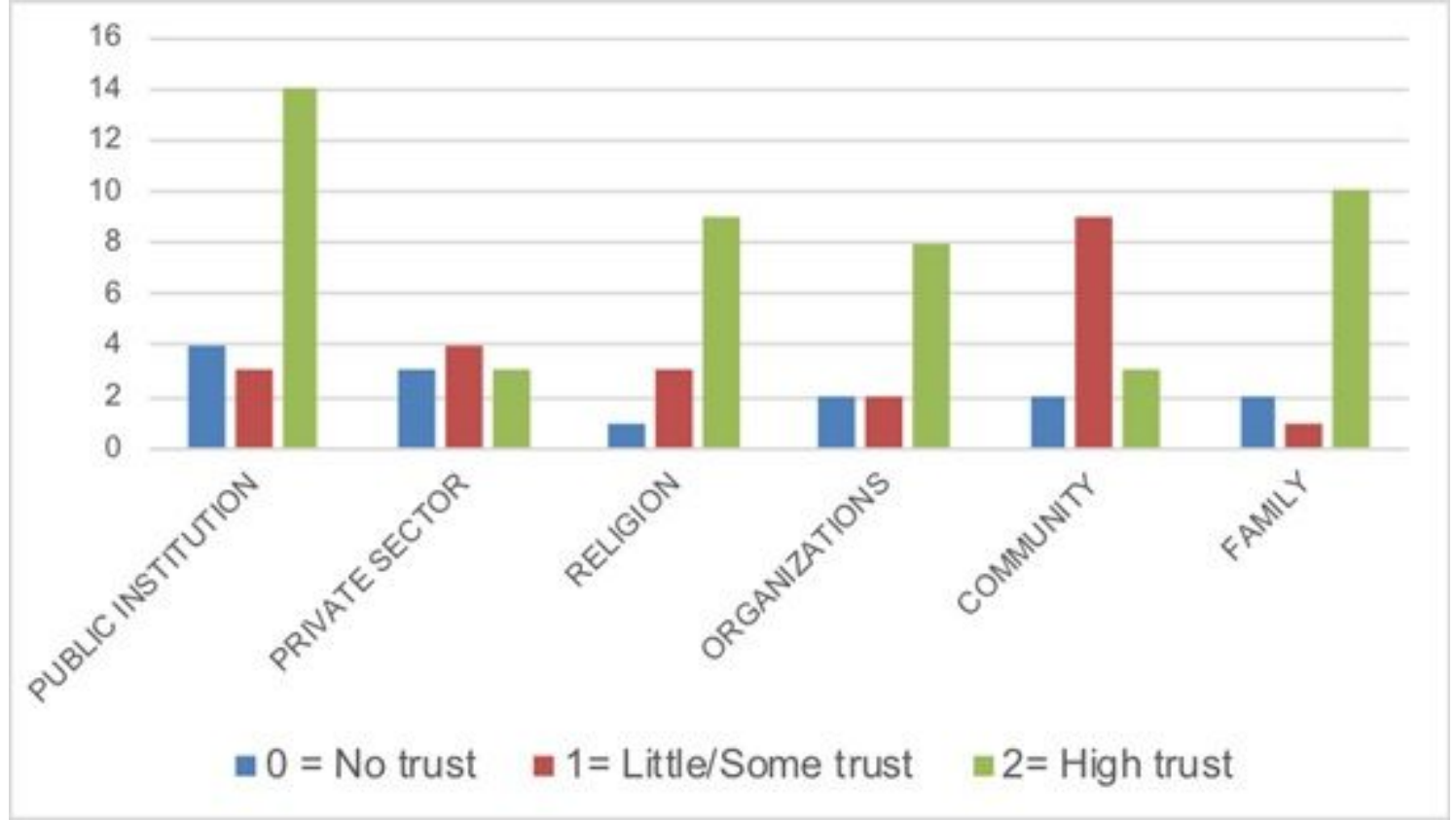

\section{Figure 4}

Levels of trust reported in resources identified by category 